\title{
Hydroxymatairesinol and Sesaminol Act Differently on Tocopherol Concentrations in Rats
}

\author{
Kanae YamashitA ${ }^{1}$, Yasushi YamadA ${ }^{1}$, Shiho KITOU $^{1}$, Saiko IkEdA ${ }^{2}$ Chisato ABE $^{3}$, \\ Niina M. SAARINEN ${ }^{4}$ and Risto SANTTI ${ }^{5}$ \\ ${ }^{1}$ Department of Food and Nutrition, Sugiyama Jogakuen University, Nagoya 464-8662, Japan \\ ${ }^{2}$ Department of Nutritional Sciences, Nagoya University of Arts and Sciences, Nissin 470-0196, Japan \\ ${ }^{3}$ Department of Food and Nutrition, Tsu City College, 514-0112 Japan \\ ${ }^{4}$ Functional Foods Forum, University of Turku, FIN-20520 Turku, Finland \\ ${ }^{5}$ Department of Anatomy, Institute of Biomedicine, University of Turku, \\ FIN-20520 Turku, Finland
}

(Received February 26, 2007)

\begin{abstract}
Summary We have previously reported that sesame seed with the tetrahydrofurofuran type lignans sesamin and sesaminol $(\mathrm{SeOH})$ produced higher tocopherol concentrations, while flaxseed with the dibenzylbutyrolactone type lignans did not cause higher tocopherol concentrations in rats. Sesame seeds also contain the dibenzylbutyrolactone type lignan 7hydroxymatairesinol (HMR). To clarify whether or not the tocopherol elevating effect is affected by the chemical structure of lignans, the effect of HMR isolated from Norway spruce, was compared with $\mathrm{SeOH}$, isolated from sesame seed. The lignans were added to a low $\alpha$-tocopherol $(10 \mathrm{mg} / \mathrm{kg})$ diet, and rats were maintained on these diets for $8 \mathrm{wk}$. The experimental diet containing $0.2 \% \mathrm{SeOH}$ elevated $\alpha$-tocopherol content in the plasma liver, kidney, and brain, but HMR $(0.2 \%$ or $0.5 \%)$ had no effects. Dietary HMR and SeOH (both in concentrations of $0.2 \%)$ were further compared in rats fed on a $\gamma$-tocopherol $(50 \mathrm{mg} / \mathrm{kg})$ containing diet. SeOH produced significantly higher $\gamma$-tocopherol content in the plasma and tissues, and significantly lower 2,7,8-trimethyl-2(2'-carboxyethyl)-6-hydroxychroman ( $\gamma$ CEHC, a $\gamma$-tocopherol metabolite) content in the urine. However, HMR did not show such effects. These results suggest that the sesame lignan $\mathrm{SeOH}$ increases tocopherol concentrations in animals by suppressing the conversion of $\gamma$-tocopherol to $\gamma$-CEHC. HMR, a structurally different plant lignan, does not have such properties. Further studies are needed to show the potential health effects associated with an increased tocopherol concentration in the body.
\end{abstract}

Key Words plant lignan, 7-hydroxymatairesinol, sesaminol, vitamin E, rat

Lignans have received a great deal of attention for their potential beneficial health effects such as antioxidative, antitumor, and hypocholesterolemic activities (1-6). There are two types of plant lignans. One is the tetrahydrofurofuran type such as sesamin and sesaminol $(\mathrm{SeOH})$, found in sesame seeds (Fig. 1), and the other is the dibenzylbutyrolactone type such as secoisolariciresinol, found in flaxseed. Recently, it was found that hydroxymatairesinol (HMR) (Fig. 1), with a structure similar to secoisolariciresinol in flaxseed, is present in substantial amounts in Norway spruce (7). It has been reported that HMR is converted to enterolactone and enterodiol (mammalian lignan) and has antitumorigenic $(8-10)$ and strong antioxidative capacity $(8)$

E-mail:kanae@sugiyama-u.ac.jp

Abbreviations: AIN, American Institute of Nutrition; ANOVA, analysis of variance; $\gamma$-CEHC, 2,7,8-trimethyl-2(2'carboxyethyl)-6-hydroxychroman; HMR, 7-hydroxymatairesinol; HPLC, high performance liquid chromatography; SDG, secoisolariciresinol diglycoside; SeOH, sesaminol; TBARS, thiobarbituric acid-reactive substances. like secoisolariciresinol in flaxseed, and further, HMR did not exhibit toxic effects in antitumorigenic studies over $9 \mathrm{wk}(10)$ or $17 \mathrm{wk}(8,9)$. It was found that HMR is also present in sesame seed though only slightly (11, 12). SeOH was discovered in unroasted sesami oil in 1986 by Fukuda et al. (13) as a new sesame lignan with strong antioxidant properties. The antioxidant capacity of $\mathrm{SeOH}$ is equal to that of HMR (14). SeOH has been shown to elevate tocopherol concentrations in plasma and tissues of experimental animals $(15,16)$.

We have previously reported that sesame seed with tetrahydrofurofuran type lignans produced higher tocopherol concentrations, but flaxseed with the dibenzylbutyrolactone type lignans did not (17). In these studies, dietary lignan contents were lower in flaxseed than in sesame seed. In the present study, we were able to obtain sufficient amounts of HMR of the dibenzylbutyrolactone type from Norway spruce, and also obtained isolated $\mathrm{SeOH}$ from sesame seed. Thus, we could examine more precisely whether or not the chemical structure of lignans was important for the induction of higher tocopherol concentrations using isolated 
HMR and $\mathrm{SeOH}$.

In the present study, we examined the comparative effects of two type lignans on tocopherol metabolism using HMR and SeOH. In Experiment 1, the $\alpha$-tocopherol raising effects of HMR and $\mathrm{SeOH}$ were examined in rats fed on a low $\alpha$-tocopherol diet, and in Experiment 2, the comparative effects of HMR and SeOH on $\gamma$-tocopherol metabolism were studied in rats fed on a $\gamma$ tocopherol fortified diet.

\section{MATERIALS AND METHODS}

Materials. $\quad \alpha$-Tocopherol was a gift of Eisai Co. (Tokyo, Japan). 7-Hydroxymatairesinol (HMR, 96.6\% purity), was isolated from Norway spruce (Picea abies) by a modification of a previously described method (7). Briefly, freeze-dried ground heartwood was soxhlet-extracted with hexane to remove nonpolar lipophilic components. The wood sample was re-extracted in the same apparatus with acetone-water $(9: 1 \mathrm{vol} / \mathrm{vol})$ and concentrated with a rotating film evaporator to give an HMR-rich lignans fraction. HMR was analyzed by combined gas chromatography-mass spectrometry. SeOH (30\% ethanol solution; $74.4 \%$ purity as solid) was donated by Takemoto Oil \& Fat Co. (Aichi, Japan). The chemical structures of HMR and $\mathrm{SeOH}$ are shown in Fig. 1. The vitamin E-stripped corn oil was purchased from Funahasi Nougyo Co. (Chiba, Japan). A vitamin Efree vitamin mixture and a mineral mixture were both made according to AIN-93 formulation (18) by Nihon Nosan Kogyo (Yokohama, Japan). Solvents used for chromatography were of high-performance liquid chro- matography (HPLC) grade. Thiobarbituric acid was purchased from Merck (Darmstadt, Germany). All other chemicals were of analytical grade.

Animals and diets. Rats were maintained in accordance with the Guidelines for Animal Experimentation of Nagoya University. Three-week-old male Wistar strain rats (Japan SLC, Inc., Shizuoka, Japan) were housed individually in stainless-steel wire-mesh cages at $24.5^{\circ} \mathrm{C}$ and $55 \%$ humidity, with a 12-h light/dark cycle, and rats were allowed free access to a non-purified diet (CE-2, CLEA Japan, Inc.) for 3-5 d and then given experimental diets (Table 1). Experimental diets were stored at $-30^{\circ} \mathrm{C}$ until used.

In Experiment 1, HMR was compared with $\mathrm{SeOH}$ using 5 different dietary groups; 1 . Vitamin E-free diet

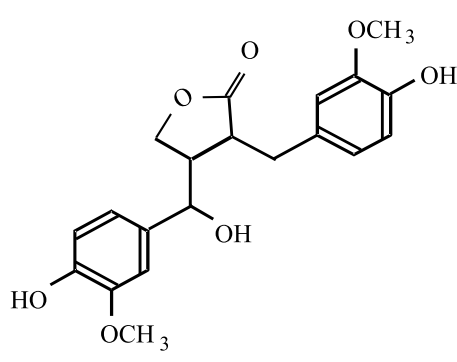

7-hydroxymatairisinol

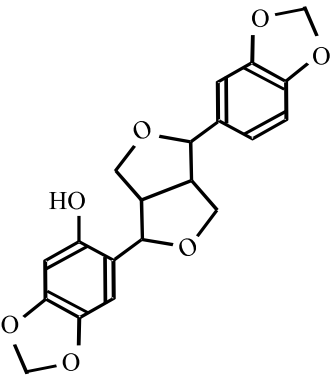

Sesaminol
Fig. 1. Chemical structure of hydroxymatairesinol (HMR) isolated from Norway spruce and sesaminol $(\mathrm{SeOH})$ isolated from sesame seed.

Table 1. Composition of diets (Experiments 1 and 2).

\begin{tabular}{|c|c|c|c|c|c|c|c|c|}
\hline & \multicolumn{5}{|c|}{ Experiment 1} & \multicolumn{3}{|c|}{ Experiment 2} \\
\hline & $\begin{array}{l}\text { Vitamin E-free } \\
\qquad(-\mathrm{E})\end{array}$ & $\alpha$-Toc & $\begin{array}{c}\alpha-\text { Toc } \\
+0.2 \% \text { HMR }\end{array}$ & $\begin{array}{c}\alpha-\text { Toc } \\
+0.5 \% \text { HMR }\end{array}$ & $\begin{array}{c}\alpha-\mathrm{Toc} \\
+0.2 \% \mathrm{SeOH}\end{array}$ & $\gamma$-Toc & $\begin{array}{c}\gamma \text {-Toc } \\
+0.2 \% \mathrm{HMR}\end{array}$ & $\begin{array}{c}\gamma \text {-Toc } \\
+0.2 \% \mathrm{SeOH}\end{array}$ \\
\hline & \multicolumn{8}{|c|}{$\mathrm{g} / \mathrm{kg}$ diet } \\
\hline Casein $^{1}$ & 200 & 200 & 200 & 200 & 200 & 200 & 200 & 200 \\
\hline L-Cysteine & 3 & 3 & 3 & 3 & 3 & 3 & 3 & 3 \\
\hline Corn starch & 467 & 467 & 467 & 467 & 467 & 467 & 467 & 467 \\
\hline Sucrose & 100 & 100 & 100 & 100 & 100 & 100 & 100 & 100 \\
\hline Stripped corn oil & 100 & 100 & 100 & 100 & 100 & 100 & 100 & 100 \\
\hline Cellulose powder & 50 & 50 & 50 & 50 & 50 & 50 & 50 & 50 \\
\hline $\begin{array}{l}\text { Mineral mixture } \\
\quad(\text { AIN-93) }\end{array}$ & 35 & 35 & 35 & 35 & 35 & 35 & 35 & 35 \\
\hline $\begin{array}{l}\text { Vitamin mixture } \\
{[\text { AIN-93(-E)] }}\end{array}$ & 10 & 10 & 10 & 10 & 10 & 10 & 10 & 10 \\
\hline Choline bitartrate & 2.5 & 2.5 & 2.5 & 2.5 & 2.5 & 2.5 & 2.5 & 2.5 \\
\hline$\alpha$-Tocopherol & & 0.01 & 0.01 & 0.01 & 0.01 & & & \\
\hline$\gamma$-Tocopherol & & & & & & 0.05 & 0.05 & 0.05 \\
\hline $\mathrm{BHT}^{2}$ & 0.014 & 0.014 & 0.014 & 0.014 & 0.014 & 0.014 & 0.014 & 0.014 \\
\hline $\mathrm{HMR}^{3}$ & & & 2 & 5 & & & 2 & \\
\hline $\mathrm{SeOH}^{4}$ & & & & & 2 & & & 2 \\
\hline
\end{tabular}

\footnotetext{
${ }^{1}$ Vitamin-free casein (Wako Pure Chemical Industries, Ltd., Osaka, Japan).

${ }^{2}$ Tert-butyl hydroxytoluene was used instead of tert-butylhydroquinone on AIN-93.

${ }^{3}$ Hydroxymatairesinol (HMR) with $96.6 \%$ purity was isolated from Norway spruce.

${ }^{4}$ Sesaminol (SeOH) was used with $30 \%$ ethanol solution; $74.4 \%$ purity as solid.
} 
$(-\mathrm{VE}) ; \quad 2 . \quad \alpha$-tocopherol-containing $(10 \mathrm{mg} / \mathrm{kg}) \quad \operatorname{diet}$ (control); 3-5. $\alpha$-tocopherol-containing diet supplemented with $0.2 \%$ HMR (0.2\% HMR), 0.5\% HMR (0.5\% HMR) or $0.2 \% \mathrm{SeOH}(0.2 \% \mathrm{SeOH})$ as shown in Table 1. Rats were fed on experimental diets for $8 \mathrm{wk}$, their body weight and food intake measured every other day, and deprived of food for the final $24 \mathrm{~h}$. Thereafter, the rats were anesthetized with Nembutal (pentobarbital $\mathrm{Na}$ ). Blood samples were drawn from the heart. Following perfusion of the liver with physiological saline it was excised, together with the kidney and brain. Plasma samples and organs were stored at $-80^{\circ} \mathrm{C}$ until use for measurements of tocopherols and thiobarbituric acid reactive substances (TBARS).

In Experiment 2, the effects of HMR- and SeOH-containing diets were compared by the concentrations of $\gamma$ tocopherol and 2,7,8-trimethyl-2(2'-carboxyethyl)-6hydroxychroman $(\gamma$-CEHC). Twelve rats were fed on a vitamin E-free diet for $4 \mathrm{wk}$. Thereafter, 6 rats were fed on a $50 \mathrm{mg} / \mathrm{kg} \gamma$-tocopherol containing diet $(\gamma$-Toc) for $3 \mathrm{~d}$ and another 6 rats with a $\gamma$-Toc diet supplemented with $0.2 \%$ HMR (study A). In study B, another 12 rats fed on a vitamin E-free diet for 4 wk were fed on a $\gamma$-Toc diet or $\gamma$-Toc diet supplemented with $0.2 \% \mathrm{SeOH}$ for $3 \mathrm{~d}$. The rats were not deprived of food, and final $24 \mathrm{~h}$ urine was collected in metabolic cages with test tubes stored in dry ice, lyophilized then stored at $-80^{\circ} \mathrm{C}$ under nitrogen until used for the determination of $\gamma$-CEHC. The urine samples of the two studies (study A with dietary HMR and study B with dietary $\mathrm{SeOH}$ ) were collected on different days. The sampling of the blood, liver, and kidney were carried out as described for Experiment 1.

Analysis of samples. Analytical procedures for the plasma and tissue samples were essentially the same as described by Yamashita et al. (15-17). $\alpha$ - and $\gamma$-tocopherol concentrations in the plasma and tissues were analyzed by HPLC according to the method of Ueda and Igarashi (19). Instrumentation used for HPLC was a Shimadzu Model LC-9A (Shimadzu, Kyoto, Japan) with a Shimadzu RF-535 fluorescence detector (Ex: 298 nm, Em: $325 \mathrm{~nm})$. The analytical column used was a Develosil 60-5 $(4.6 \phi \times 250 \mathrm{~mm}$, Nomura Chemical, Aichi, Japan). The mobile phase was hexane and isopropyl alcohol $(99: 1, \mathrm{v} / \mathrm{v})$, and the flow rate was $1 \mathrm{~mL} /$ min. Lipid peroxides in the plasma were determined as thiobarbituric acid reacting substances (TBARS) by the fluorometric method of Yagi (20), and TBARS in the liver, kidney and brain were determined by the thiobarbituric acid colorimetric method of Ohkawa et al. (21). The concentrations of TBARS are represented in terms of nanomoles of malondialdehyde (MDA).

Urinary excretion of $\gamma$-CEHC was analyzed essentially using the method described by Ikeda et al. (22). Both conjugated and unconjugated $\gamma$-CEHC in the urine was methylated and extracted using the method of Kiyose et al. (23), and the concentration was determined using HPLC with an electrochemical detector. Water $(60 \mathrm{~mL})$ was added to lyophilized urine collected for $24 \mathrm{~h}$, and $0.5 \mathrm{~mL}$ of the urine sample was added to $0.1 \mathrm{~mL}$ of 500 $\mathrm{g} / \mathrm{L}$ ascorbic acid and $1 \mathrm{~mL}$ of $0.54 \mathrm{mmol} / \mathrm{L}$ EDTA. The urine sample was methylated in $3 \mathrm{~mol} / \mathrm{L}$ methanolic hydrochloric acid at $60^{\circ} \mathrm{C}$ for $1 \mathrm{~h}$ under nitrogen, and the methylated tocopherol metabolite was extracted with hexane. The hexane was evaporated by nitrogen, and the residue was dissolved in $100 \mu \mathrm{L}$ of $45 \%(\mathrm{v} / \mathrm{v})$ acetonitrile containing $50 \mathrm{mmol} / \mathrm{L}$ sodium perchlorate; $10 \mu \mathrm{L}$ of this solution was subjected to HPLC. Instrumentation used for HPLC was a Shimadzu LC-10AS with a Coulochem electrochemical detector (MC Medical, Osaka, Japan) and an ODS-3 column $(250 \times 2.1$ $\mathrm{mm}$, GL Science, Tokyo, Japan). The mobile phase was $45 \%(\mathrm{v} / \mathrm{v})$ acetonitrile containing $50 \mathrm{mmol} / \mathrm{L}$ sodium perchlorate, $\mathrm{pH} 3.6$, and the flow rate was $0.2 \mathrm{~mL} / \mathrm{min}$. For coulometric detection, the analytical and guard cells were set to $+0.4 \mathrm{~V}$ and $+0.45 \mathrm{~V}$ respectively.

Statistical analysis. Data were expressed as means \pm SE, $n=6$. Results were analyzed using one-way ANOVA with Fisher's posthoc test in Experiment 1 and using Student's $t$ test in Experiment 2. Differences were considered statistically significant at $p<0.05$.

\section{RESULTS}

In Experiment 1, we compared the $\alpha$-tocopherol-raising properties of $\mathrm{HMR}$ and $\mathrm{SeOH}$ in rats fed on low $\alpha$ tocopherol diets for $8 \mathrm{wk}$. No significant effects of the HMR- and SeOH-containing diets on animal growth or food intake were observed (data not shown). The addition of $0.2 \%$ or $0.5 \%$ HMR to the diet did not elevate $\alpha$ tocopherol content in the plasma or tissues. Instead, rats on the HMR-diet showed lower $\alpha$-tocopherol content in the liver. In contrast to HMR, the addition of $0.2 \% \mathrm{SeOH}$ significantly increased $\alpha$-tocopherol concentrations in the plasma and tissues (Fig. 2).

The antioxidativity of the lignan diets were evaluated by measuring the TBARS concentrations in plasma and tissues. The TBARS concentrations in plasma and tissues were significantly lower in rats fed on a low $\alpha$-tocopherol diet compared to rats fed on a vitamin $\mathrm{E}$ free diet (Fig. 3). No statistically significant differences in plasma or tissue TBARS concentrations were measured in rats fed on lignan-supplemented diets as compared to the low $\alpha$-tocopherol control.

In Experiment 2, the effects of HMR and $\mathrm{SeOH}$ were studied on $\gamma$-tocopherol conversion to $\gamma$-CEHC in rats fed on $\gamma$-tocopherol-containing diets after a 4 -wk vitamin E deprivation. $\gamma$-Tocopherol concentrations in the plasma, liver, and kidney are shown in Fig. 4. HMR did not increase the $\gamma$-tocopherol content in plasma and tissues. Instead, a small but statistically significant decrease of $\gamma$-tocopherol content was observed in the liver and kidney. In contrast to HMR, dietary SeOH significantly increased $\gamma$-tocopherol content in the plasma, liver, and kidney as compared to controls on the lignan-free diet. The supplementation of the diet with HMR showed a slight (statistically insignificant) increase of $\gamma$-CEHC in urine. In the SeOH group, $\gamma$ $\mathrm{CEHC}$ in urine was significantly lower than in the control group (Fig. 5). 

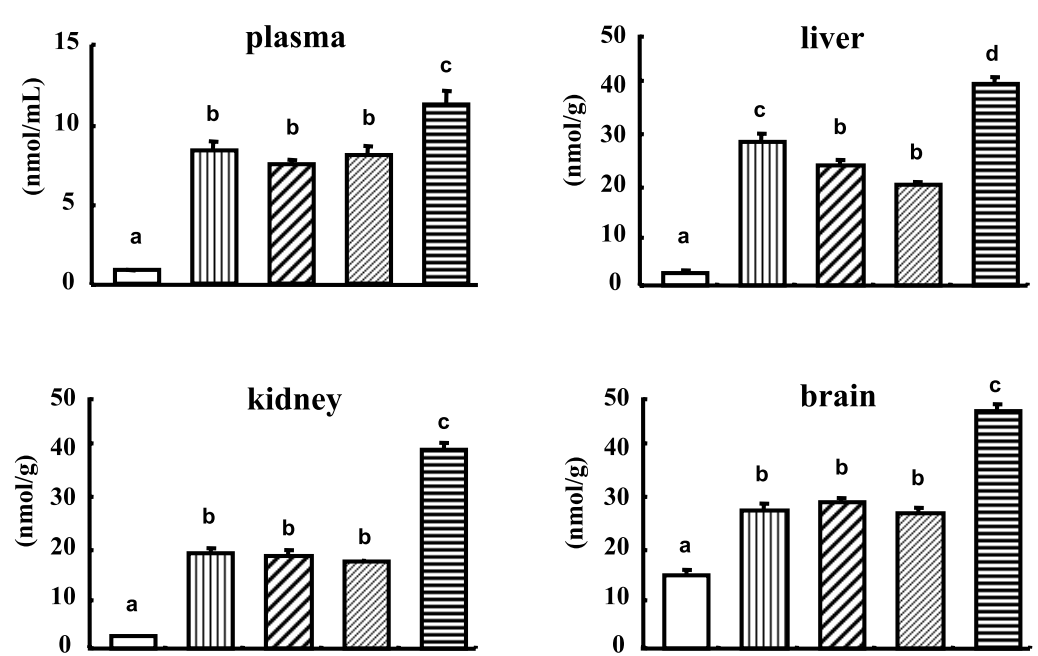

Fig. 2. $\alpha$-Tocopherol concentrations in plasma $(\mathrm{nmol} / \mathrm{mL})$, liver, kidney and brain $(\mathrm{nmol} / \mathrm{g}$ wet tissues) of rats fed for $8 \mathrm{wk}$ on a vitamin $\mathrm{E}$ free diet, $10 \mathrm{mg} / \mathrm{kg} \alpha$-tocopherol-containing diet, $10 \mathrm{mg} / \mathrm{kg} \alpha$-tocopherol and $2 \mathrm{~g} / \mathrm{kg}$ hydroxymatairesinol (HMR)-containing diet, $10 \mathrm{mg} / \mathrm{kg} \alpha$-tocopherol and $5 \mathrm{~g} / \mathrm{kg} \mathrm{HMR}$-containing diet and $10 \mathrm{mg} / \mathrm{kg} \alpha$-tocopherol and $2 \mathrm{~g} / \mathrm{kg}$ sesaminol (SeOH)-containing diet (Exp. 1). Values are mean \pm SE, $n=6$. Different letters indicate a statistically significant difference $(p<0.05)$.

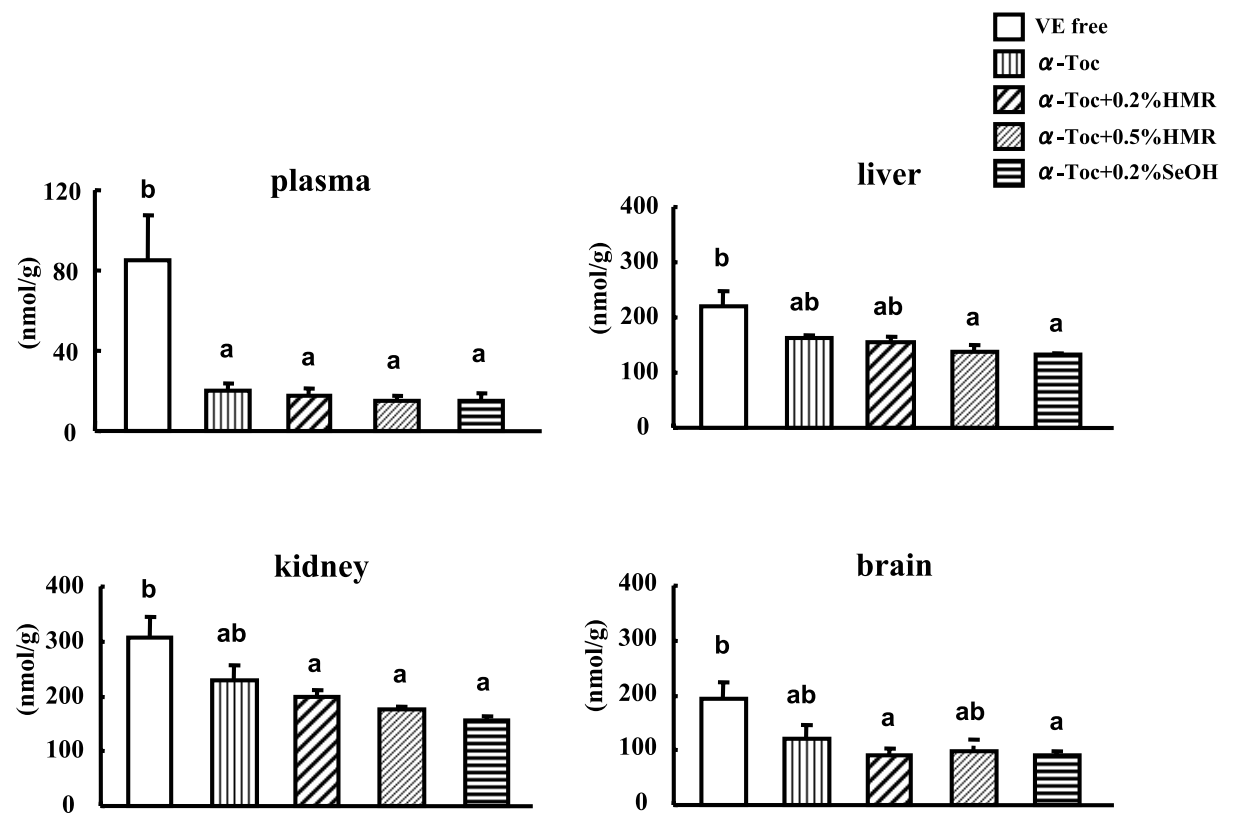

Fig. 3. TBARS concentrations in plasma, liver, kidney and brain of rats fed for 8 wk vitamin $\mathrm{E}$ free, $\alpha$-tocopherol, $\alpha$-tocopherol with 0.2\% HMR, $\alpha$-tocopherol with $0.5 \% \mathrm{HMR}$ and $\alpha$-tocopherol with $0.2 \% \mathrm{SeOH}$ diets (Exp. 1 ). The concentrations of TBARS are represented in terms of nmoles of malondialdehyde (MDA). Values are mean \pm SE, $n=6$. Different letters indicate a statistically significant difference $(p<0.05)$.

\section{DISCUSSION}

We have previously reported that dietary sesame seed elevated vitamin $\mathrm{E}$ concentration in rats (15-17). The effect is mainly due to sesamin, sesamolin and sesaminol $(\mathrm{SeOH})$, the most abundant plant lignans in sesame seed. In recent years, the metabolism of vitamin E (tocopherols and tocotrienols) has been reinvestigated and new metabolites were identified (24-26). It was demonstrated that $\omega$-oxidation of the side chain by cytochrome P450 enzymes is a major pathway of vitamin E metabolism, and metabolites still contain an intact chroman ring. For example, $\gamma$-tocopherol metabolite is 2,7,8-trimethyl-2(2'-carboxyethyl)-6-hydroxychroman $(\gamma$-CEHC). The vitamin E metabolites are mainly excreted in the urine and bile (23). It has been reported by 

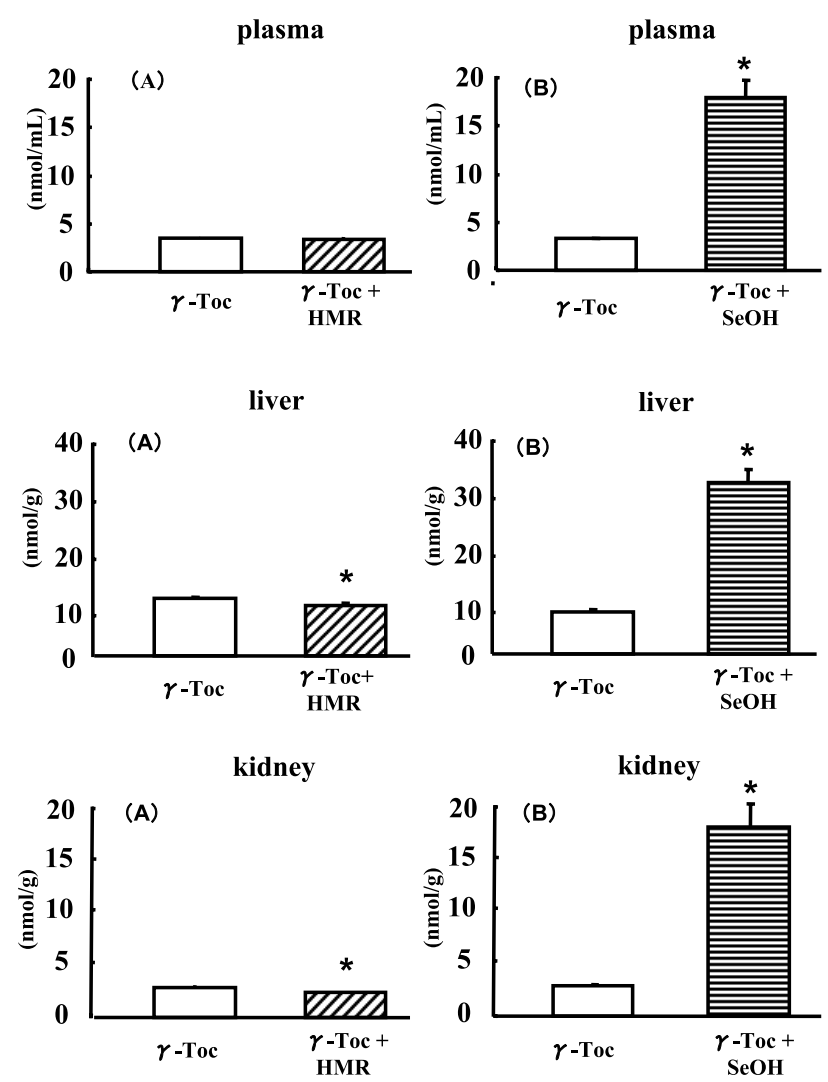

Fig. 4. Effects of HMR and SeOH on $\gamma$-tocopherol concentrations in plasma, liver and kidney. Twelve rats were fed a vitamin E-free diet for $4 \mathrm{wk}$, with 6 rats fed for $3 \mathrm{~d}$ a $50 \mathrm{mg} / \mathrm{kg} \gamma$-tocopherol-containing diet $(\gamma$-Toc) and another 6 rats a $50 \mathrm{mg} / \mathrm{kg} \gamma$-tocopherol with 0.2\% HMR-containing diet (A). On the other days, 12 rats were fed a vitamin E-free diet for $4 \mathrm{wk}$, with one group fed for $3 \mathrm{~d}$ a $50 \mathrm{mg} / \mathrm{kg} \gamma$-tocopherol-containing $\operatorname{diet}(\gamma$-Toc), and the other group a $50 \mathrm{mg} / \mathrm{kg} \gamma$ tocopherol with $0.2 \% \mathrm{SeOH}$-containing diet (B). The rats were not deprived of food before sacrifice. Values are mean $\pm \mathrm{SE}$, $n=6$. An asterisk indicates a significant difference from the $\gamma$-Toc group at $p<0.05$ by the Student's $t$-test.
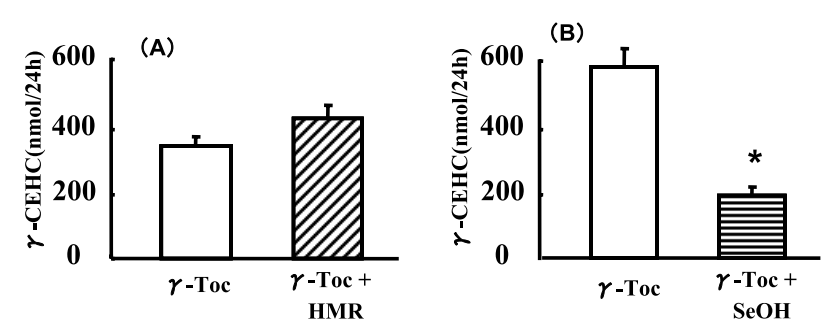

Fig. 5. Urinary excretion of 2,7,8-trimethyl-2(2'-carboxyethyl)-6-hydroxychroman ( $\gamma$-CEHC) of rats is explained in Fig. 4 legend. The urine was collected for the last $24 \mathrm{~h}$ before sacrifice. Values are mean \pm SE, $n=6$. An asterisk indicates a significant difference from the $\gamma$-Toc group at $p<0.05$ by Student's $t$-test.

Parker et al. in vitro $(27,28)$ and by our laboratory in vivo (22) that sesame lignans inhibited CYP enzymes, and produced lower CEHCs. In the present study, we examined whether or not the lignan chemical structure of lignan was important for the induction of higher tocopherol concentrations using HMR as the dibenzylbutyrolactone type and $\mathrm{SeOH}$ as the tetrahydrofurofuran type. We compared the effects of $\mathrm{HMR}$ and $\mathrm{SeOH}$ on $\alpha$ - and $\gamma$-tocopherol concentrations and $\gamma$-tocopherol metabolite, and $\gamma$-CEHC in the urine of rats fed $\alpha$ - and $\gamma$-tocopherol containing diets. As shown in Fig. 2, SeOH significantly elevated plasma and tissue $\alpha$-tocopherol concentrations, but HMR did not produce such effects.

At present, two possible mechanisms are proposed for the higher tocopherol concentrations induced by food components. One is the prevention of vitamin E degradation, and the other is the synergistic sparing effects of vitamin $\mathrm{E}$ by antioxidants in food. We have already reported that $\mathrm{SeOH}$ produced higher tocopherol concentrations by inhibition of tocopherol degradation to CEHC (22). As shown in Fig. 5, SeOH produced significantly lower $\gamma$-CEHC in urine as in previous experiments (22), but HMR did not suppress $\gamma$-CEHC excretion in urine. These results suggest that CYP enzyme inhibition by sesame lignans might be the main cause of higher tocopherol concentrations in rats, since $\mathrm{SeOH}$ causes significantly higher tocopherol concentration and lower CEHC excretion, while HMR causes a slight but statistically significant decrease of $\gamma$-tocopherol concentration in the liver and slightly higher $\gamma$-CEHC excretion (Figs. 4 and 5). The present experiments showed that the effects of HMR on tocopherol concentrations were slight, though Frank and associates (29) reported that the flaxseed lignan, SDG, of the dibenzylbutyrolactone type caused a 2-fold reduction in the levels of $\alpha$ - and $\gamma$-tocopherols in rats. However, they reported that they could not explain the reasons.

It has been suggested that antioxidant properties such as those seen in vitamin C (30) produce higher 
vitamin E levels by the sparing action of vitamin E. Both $\mathrm{HMR}$ and $\mathrm{SeOH}$ have strong antioxidant properties. In experiment $1, \alpha$-tocopherol concentrations in the plasma and tissues of rats fed a low $\alpha$-tocopherol diet (Fig. 2) were substantially higher than in our previous study (16) (plasma $\alpha$-tocopherol $7.65 \pm 0.51 \mathrm{nmol} / \mathrm{mL}$ in the present and $2.14 \pm 0.16 \mathrm{nmol} / \mathrm{mL}$ previously, respectively). The previous diets containing $10 \mathrm{mg} / \mathrm{kg}$ low $\alpha$-tocopherol and 10\% high fat caused the lower $\alpha$ tocopherol and higher TBARS concentrations in rats. The present diets contained the same $10 \mathrm{mg} / \mathrm{kg}$ low $\alpha$ tocopherol and 10\% high fat, but the diet contained $3 \mathrm{~g} / \mathrm{kg}$ L-cystine and $14 \mathrm{mg} / \mathrm{kg}$ butylhydroxytoluene (BHT) with antioxidant properties similar to the AIN93 formulation (AIN-93 contains not BHT but butylhydroxyquinone). The higher antioxidant property in the present diets may account for the higher $\alpha$-tocopherol concentrations in the plasma and tissues and significantly lower TBARS concentrations as compared to the vitamin E free group (Fig. 3). Kamal-Eldin et al. also reported that BHT induced significantly higher $\alpha$-tocopherol in the plasma and tissues in rats (31). The addition of HMR or $\mathrm{SeOH}$ to diets was expected to suppress TBARS concentrations in the plasma and tissues because these diets were low in a-tocopherol (10 mg/ $\mathrm{kg}$ ), but neither HMR nor SeOH induced significant suppression of TBARS concentrations in comparison with the low $\alpha$-tocopherol control diet (Fig. 3). Thus, we supposed that dietary cystine and BHT might interfere with the lignan effects on tocopherol and TBARS concentrations. In addition, further increases of $\alpha$-tocopherol by $\mathrm{SeOH}$ had no affect on TBARS concentrations in the present experiment. This contradicts the findings in our previous study which showed a decreased concentration of TBARS after the maintenance of the rats on $\mathrm{SeOH}$ diets (16).

Kamal-Eldin et al. (31-33) and Frank (34) have repeatedly reported that the sesame lignan sesamin elevated only $\gamma$-tocopherol, but not $\alpha$-tocopherol. However, our previous reports and present results showed that sesame seed, sesamin and sesaminol induced higher $\alpha$-tocopherol concentrations (15-17, 22, 3537). Further, Parker et al. (27) and Sontag and Parker (28) reported that sesamin inhibited the metabolism of $\alpha$-tocopherol to $\alpha$-CEHC as well as $\gamma$-tocopherol to $\gamma$ $\mathrm{CEHC}$ in in vitro studies. They observed that CYP4F2 enzymes affected $\gamma$-tocopherol more strongly than $\alpha$ tocopherol (28). We agree that sesame lignans produce more intense effects on $\gamma$-tocopherol than on $\alpha$-tocopherol.

These findings indicate that the effects of dietary lignans on tocopherol concentrations in rats vary significantly. So far, among lignans, only the furofuran type compounds such as sesamin and sesaminol have been shown to increase tocopherol concentrations in plasma and tissues. Whether the amplifying effect of lignans on tocopherol concentration is specific to these structures is a question that needs further investigation.

\section{Acknowledgments}

This study was supported by a Grant-in-Aid for Scientific Research (B) from the Ministry of Education, Culture, Sports, Science and Technology of Japan (No. 14380046). We are grateful to Reiko Kashima, Aya Kanzaki, Kana Kobayashi, Natsuko Sawato, Mina Tada, and Mariko Terakado for their technical assistance.

\section{REFERENCES}

1) Nakai M, Harada M, Nakahara K, Akimoto K, Shibata H, Miki W, Kiso Y. 2003. Novel antioxidative metabolites in rat liver with ingested sesamin. J Agric Food Chem 51: 1666-1670.

2) Sugano M, Inoue T, Kobe K, Yoshida K, Hirose N, Shinmen Y, Akimoto K, Amachi Y. 1990. Influence of sesame lignans on various lipid parameters in rats. Agric Biol Chem 54: 2669-2673.

3) Hirose N, Inoue T, Sugano M, Akimoto K, Shimizu S, Yamada H. 1991. Inhibition of cholesterol absorption and synthesis in rats by sesamin. J Lipid Res 32: 629638.

4) Serraino M, Thompson LU. 1991. The effect of flaxseed supplementation and early markers of mammary carcinogenesis. Cancer Lett 60: 135-142.

5) Thompson LU, Seidl MM, Rickard SE, Orcheson LJ, Fong HHS. 1996. Antitumorigenic effect of a mammalian lignan precursor from flaxseed. Nutr Cancer 26: 159-165.

6) Prasad K. 1997. Dietary flax seed in prevention of hypercholesterolemic atherosclerosis. Atherosclerosis 132: $69-76$.

7) Ekman R. 1976. Analysis of lignans in Norway spruce by combined gas chromatography-mass spectrometry. Holzforschung 30: 79-85.

8) Saarinen NM, Wärri A, Mäkelä SI, Eckeman C, Reunanen M, Ahotupa M, Salmi SM, Franke AA, Kangas L, Santti R. 2000. Hydroxymatairesinol, a novel entrolactone precursor with antitumor properties from coniferous tree (Picea abies). Nutr Cancer 36: 207-216.

9) Saarinen NM, Huovinen R, Wärri A, Mäkelä SI, Valentin-Blasini L, Needham L, Eckeman C, Collan YU, Santti R. 2001. Uptake and metabolism of hydroxymatairesinol in relation to its anticarcinogenicity in DMBAinduced rat mammary carcinoma model. Nutr Cancer 41: 82-90.

10) Bylund A, Saarinen N, Zhang J-X, Bergh A, Widmark A, Johansson A, Lundin E, Adlercreutz H, Hallmans G, Stattin P, Mäkelä S. 2005. Anticancer effects of a plant lignan 7-hydroxymatairesinol on a prostate cancer model in vivo. Exp Biol Med 230: 217-223.

11) Peñalvo JL, Heinonen S-M, Aura A-M, Adlercreutz H. 2005. Dietary sesamin is converted to enterolactone in humans. J Nutr 135: 1056-1062.

12) Liu Z, Saarinen NM, Thompson LU. 2006. Sesamin is one of the major precursors of mammalian lignans in sesame seed (Sesamum indicum) as observed in vitro and in rats. J Nutr 136: 906-912.

13) Fukuda Y, Nagata M, Osawa T, Namiki M. 1986. Contribution of lignan analogues to antioxidative activity of refined unroasted sesame seed oil. J Am Oil Chem Soc 63: 1027-1031.

14) Katsuda S, Yoshida M, Saarinen NM, Smeds A, Nakae D, Santti R, Mawkawa A. 2004. Chemopreventive effects of hydroxymatairesinol on uterine carcinogenesis in Donryu rats. Exp Biol Med 229: 417-424. 
15) Yamashita K, Nohara Y, Katayama K, Namiki M. 1992. Sesame seed lignans and $\gamma$-tocopherol act synergistically to produce vitamin E activity in rats. J Nutr 122: 2440-2446.

16) Yamashita K, Iizuka Y, Imai T, Namiki M. 1995. Sesame seed and its lignans produce marked enhancement of vitamin $\mathrm{E}$ activity in rats fed a low $\alpha$-tocopherol diet. Lipids 30: 1019-1028.

17) Yamashita K, Ikeda S, Obayashi M. 2003. Comparative effects of flaxseed and sesame seed on vitamin $\mathrm{E}$ and cholesterol levels in rats. Lipids 38: 1249-1255.

18) American Institute of Nutrition. 1993. AIN-93 purified diets for laboratory rodents: final report of the American Institute of Nutrition Ad Hoc Writing Committee on the reformulation of the AIN-76A rodent diet. J Nutr 123: 1939-1951.

19) Ueda T, Igarashi O. 1987. New solvent system for extraction of tocopherols from biological specimens for HPLC determination and the evaluation of 2,2,5,7,8pentamethyl-6-chromanol as an internal standard. $J$ Micronutr Anal 3: 185-198.

20) Yagi K. 1976. A simple fluorometric assay for lipoperoxides in plasma. Biochem Med 15: 212-216.

21) Ohkawa H, Ohishi N, Yagi K. 1979. Assay for lipid peroxides in animal tissues by tiobarbituric acid reaction. Anal Biochem 95: 351-358.

22) Ikeda $S$, Tohyama T, Yamashita K. 2002. Dietary sesame seed and its lignans inhibit 2,7,8-trimethyl-2(2'-carboxyethl)-6-hydroxychroman excretion into urine of rats fed $\gamma$-tocopherol. J Nutr 132: 961-966.

23) Kiyose C, Saito H, Kaneko K, Hamamura K, Tomioka M, Ueda T, Igarashi O. 2001. $\alpha$-Tocopherol affects the urinary and biliary excretion of 2,7,8-trimethyl-2(2'-carboxyethl)-6-hydroxychroman, $\gamma$-tocopherol metabolite, in rats. Lipids 36: 467-472.

24) Chiku S, Hammura K, Nakamura T. 1984. Novel urinary metabolite of $\mathrm{d}-\delta$-tocopherol in rats. J Lipid Res $\mathbf{2 5}$ : $40-48$.

25) Schultz M, Leist M, Petrzika M, Gassmann B, BrigeliusFlohé R. 1995. Novel urinary metabolite of $\alpha$-Tocopherol, 2,5,7,8-tetra-methyl-2-(2-carboxyethyl)-6-hydroxychoman, as an indicator of an adequate vitamin E supply? Am J Clin Nutr 62: 1527-1534.

26) Radosavac D, Graf P, Podlidori MC, Sies H, Stahl W. 2002. Tocopherol metabolites 2,5,7,8-tetra-methyl-2(2-carboxyethyl)-6-hydroxychoman $(\alpha$-CEHC) and 2,7,8- trimethyl-2-(2-carboxyethyl)-6-hydroxychoman ( $\gamma$-CEHC) in human serum after a single dose of natural vitamin E. Eur J Nutr 41: 119-124.

27) Parker RS, Sontag RS, Swanson JE. 2000. Cytochrome P450 3A-dependent metabolism of tocopherols and inhibition by sesamin. Biochem Biophys Res Commun 277: 531-534.

28) Sontag TJ, Parker RS. 2002. Cytochrome P450 $\omega$ hydroxylase pathway of tocopherol catabolism. J Biol Chem 277: 25290-25296.

29) Frank J, Eliasson C, Leroy-Nivard D, Budek A, Lundh T, Vessby B, Åman P, Kamal-Eldin A. 2004. Dietary secoisolariciresinol diglucoside and its oligomers with 3hydroxy-3-methyl glutaric acid decrease vitamin $\mathrm{E}$ levels in rats. Br J Nutr 92: 169-176.

30) Igarashi O, Yanekawa Y, Fujihara Y. 1991. Synergistic action of vitamin $\mathrm{E}$ and vitamin $\mathrm{C}$ in vivo using a new mutant of Wistar-strain rats, ODS, unable to synthesize vitamin C. J Nutr Sci Vitaminol 37: 359-369.

31) Kamal-Eldin A, Frank J, Razdan A, Tengblad S, Basu S, Vessby B. 2000. Effects of dietary phenolic compounds on tocopherol, cholesterol, and fatty acids in rats. Lipids 35: 427-435.

32) Kamal-Eldin A, Pettersson D, Appelqvist LA. 1995. Sesamin (a compound from sesame oil) increases tocopherol levels in rats fed ad libitum. Lipids 30: 499-505.

33) Ross AB, Chen Y, Frank J, Swanson JE, Parker RS, Kozubek A, Lundh T, Vessby B, Åman P, Kamal-Eldin A. 2004. Cereal alkylresorcinols elevate $\gamma$-tocopherol levels in rats and inhibit $\gamma$-tocopherol metabolism in vitro. J Nutr 134: 506-510.

34) Frank J. 2005. Beyond vitamin E supplementation: An alternative strategy to improve vitamin E status. J Plant Physiol 162: 835-843.

35) Yamashita K, Ikeda S, Iizuka Y, Ikeda I. 2002. Effect of sesaminol on plasma and tissue $\alpha$-tocopherol and $\alpha$ tocotrienol concentrations in rats fed a vitamin E concentrate rich in tocotrienols. Lipids 37: 351-358.

36) Ikeda S, Toyoshima K, Yamashita K. 2001. Dietary sesame seeds elevate $\alpha$ - and $\gamma$-tocotrienol concentrations in skin and adipose tissue of rats fed the tocotrienol-rich fraction extracted from palm oil. J Nutr 131: 28922897.

37) Abe C, Ikeda S, Yamashita K. 2005. Dietary sesame seeds elevate $\alpha$-tocopherol concentration in rat brain. $J$ Nutr Sci Vitaminol 51: 223-230. 